and those influenced by the "pures," hold that the title of doetor and the degree of M.D: are titles which ought to belong exclusively to themselves? Most undoubtedly they will! The College of Physicians introduced into Sir James Graham's Bills a clause which would have been attended with the same consequences. In one Bill these words occur:"None but physicians shall be allowed to use the title of doctor."

Physicians have always endeavoured to keep in check the advancement of the general practitioner, by monopolizing all the honourable titles and offices in the profession, and branding the general practitioner with the druggist name of apothecary. Why should not the general practitioner or surgeon be a doctor of medicine, as well as the physician, if he chooses to be at the expense and trouble of obtaining it? This, how. ever, will not suit the grandees; there must be some check put to our acquiring knowledge, or we shall soon eclipse the little men with big names.

If such a clause as this were to be enacted into a law, hundreds of surgeons in general practice would find themselves deprived of a title (and the social rank which it confers) which they have as much right to as any physician.

Mark the injustice of the case. A physician who is only member of a College of Physicians, and who is not a doctor of medicine of any university, would be able to impose on the public, by signing M.D. after his name, and assuming the title of doctor, and this without being liable to fine, or receiving any other check. A general practitioner who is a Fellow of the Royal College of Surgeons, and doctor of medicine of the University of London, would thus be liable to penalties, if he dared imply that he was a physician, by using his degree, or styling himself a doctor!!

General practitioners, be on your guard! "Lions and their providers" are on their prowl, and the jackals would sacrifice ye, that they may share the spoil with their masters.

Bristol, March, 1848 .

$$
\text { I remain, Sir, yours very truly, }
$$

J. St. J.' Parsons

Fellow of the Royal College of Surgeons in London, but now degraded into the lowest rank in that of England.

\section{THE PROPOSED NEW CHARTERS.} To the Editor of $\mathrm{THE}$ Lancer.

Sin,-Would you have the goodness to inform me, if in the event of the new and secret charters being granted, a L.S.A., M.R.C.S., and an M.D. of a British university, having obtained the degree of Doctor of Medicine since 1842, would be liable to a legal penalty for prefixing the title of Doctor to his name; if so, what is to become of the unfortunates who are graduates in medicine of a British university?

I am, Sir, your obedient servant,

S. G. $O$.

** We have not yet seen the charters, and consequently we are unwilling yet to offer an opinion on the subject. The whole question ought now to be maturely considered by the profession. The old corporations of London state that they are willing to make concessions-great concessions-in order to effect an amicable arrangement. If this be true, let us take them at their word. We fear that the question cannot be settled without calling an aggregate meeting of the members of the profession in London. Where all are so deeply interested, all ought to be consulted.-ED, $\mathrm{L}$.

\section{THE PROPOSED NEW CHARTER TO THE COLLEGE OF PHYSICIANS.}

THE REGISTRATION OF GRADUATES IN MEDICINE. To the Editor of The LaNCET.

SIR,-Allow me to call your attention to the position in which many who have taken the degree of doctor in medicine at a university in the United Kingdom of Great Britain and Ireland, since the 1st day of January, 1842, will be placed, if the fifth clause of the intended Charter to the College of Physicians, in its present state, pass into a law.

A clause should certainly be introduced to enable medical men, who have obtained a degree of doctor in medicine by regular examination, from any British university, at any date prior to the granting of the intended Charter, to register in the same manner as those who had their diploma before the Ist of January, 1842, or a great injustice will be done them.

The person holding a diploma dated subsequently will be placed in a most unjust position; and especially so if he be liable to any legal penalty for prefixing the title of doctor to his name.

Surely, in the present day, when it is so desirable that the most liberal feelings should be cultivated among the members of the profession, it would be most dangerous, most impolitic, and most unjust, to prohibit those individuals who possess a degree of doctor in medicine from a British university, being duly recognised as legally-qualified doctors in medicine.

From the liberal views and the untiring interest which you have manifested for the honour and welfare of your professional brethren, I am emboldened, as a constant reader, to submit for your consideration-whether it would not be an act of justice towards those who have availed themselves of their British doctorate, obtained, after regular examination, from a British university at any period subsequently to the 1st of January, 1842, to insert a clause by which such persons shall be protected. Trusting that you will endeavour to protect those who at present possess a British doctorate, and that you will spare no effort to prevent the proposed Charter from having all the invidious and cruelly retrospective consequences of an ex post facto law, I am, Sir, your obedient servant,

March, 1848. L.S.A., M.R.C.S.L., \& M.D. British University:

\section{MEDICAL REFORM-THE LAST ATTEMPT.}

\section{To the Editor of The Lancer.}

Srr, - I took the liberty of pointing ont one of the beauties of the new scheme of medical reform: will you now allow me to draw the attention of those whom it may concern to another.

"That those persons shall be entitled to be registered as surgeons who shall have been admitted as fellows or members by the Royal College of Surgeons. That the members of the College of Surgeons, who dispense medicines, or supply medicines to their patients, shall be required to enrol themselves in the College of General Practitioners, and to be registered as surgeons and general practitioners; and after the passing of this Act, members of the Royal College of Surgeons shall nat be registered as surgeons unless they be also admitted as members of the Royal College of General Practitioners, and registered both as surgeons and general practitioners."

From this it appears, that while there is nothing to prevent the fellows of the College from carrying on a smart stroke of business in the apothecary line, without detriment to their surgical purity, the members who shall be found guilty of similar contamination are for this reason to be let down and registered as a "lower grade" or not at all! Will this be tolerated ? I think not. I am much mistaken if the "secret, black, and midnight hags," who presided over the cookery of this delectable mess, do not find, ere long, that, like their celebrated prototypes in "Macbeth," they have been employed in brewing a "charm of powerful trouble."

The more I think upon the present state of the medical world the more plainly I see that it is not mere reform that is wanted. It is of no use to patch up the old corporations. The nuisance must be abolished, and a clear stage made to start upon, if medical legislation is ever to be anything respectable. The sooner we come all to see this the better.

London, March, 1848. I am, Sir, your obedient servant, An Old Member of the College.

HEALTH OF TOWNS BILL.

Reply of the Right Honourable Lord Morpeth, M.P., to

F. S. Garlick, Esq., Surgeon.

To the Editor of THE LANCET.

Office of Woods, \&c, March 2, 1848 .

SIR,-In reply to your letter of the 29 th ultimo, I appre* hend the medical profession have entirely misconstrued the intentions of the government in their behalf, and that the Bill will provide for them quite as much as parliament will be prepared to concede.-I am, Sir, your obedient servant, F. s. Garlick, Esq.

MoRPeTH.

On the receipt of the preceding note, $I$ addressed the following communication to his Lordship:-

To the Right Honourable Lord Morpeth, M.P. 5 , Cheapside, Halifax.

Mx LORD,-I duly received your Lordship's note in reply to my communication of the $29 \mathrm{th}$ ultimo.

I do not know, my Lord, how there can be any misconstruction on the part of the medical profession, as your Lordship would seem to intimate, when an officer so important as a 
"medical officer of health" is not distinctly recognised, and duly provided for, in the proposed Bill. I trust, however, this point will be fully and fairly discussed, and that the pro. fession may place implicit reliance on your Lordship's assurance that "government will provide for them quite as much as parliament will be prepared to concede."

Finally, my Lord, I am ready to admit that if the Bill pass, even as it is, it will confer an incalculable amount of good, and will connect your Lordship's name with one of the wisest and most benevolent acts of the legislature.-I have the honour to be, my Lord, your Lordship's obedient servant, March, $18 \pm 8$. Fred. Surth Garlick.

\section{To the Editor of THe LaxceT.}

The Parade, Birmingham, March 8, 1848.

Mx DEAR SIR,--Knowing the great interest you take in everything calculated to promote the interests of the medical profession, I beg to transmit you a copy of Lord Morpeth's reply to my application to him, recommending the appointment of union surgeons as sanitary officers under his Public Health Bill.-I am, my dear Sir, yours very faithfully,

T. Wakley, Esq., M.P., \&c.

D. D. GOURLEX.

\section{Reply of Lord Morpeth to D. D. Gourley, Esq.}

Oftice of Woods, March, 1818.

SrR,-I am much obliged to you for your communication of the 4 th instant. I apprehend it would be in the power of the local board to appoint the union medical officers, but I do not know it would be wise to make it compulsory.

I am, Sir, your much obliged and obedient servant,

D. D. Gourley, Esq.

Morpeta.

\section{ASYLUMS FOR INCURABLE LUNATICS. To the Editor of The Larcet.}

SrR,-Amongst the many institutions, hospitals, \&c., which are the glory of our land, $I$ can but feel there is still one class unprovided for, the "incurable lunatic." A superficial observer may point to St. Luke's, Bethlehem, or the county asylums. At the two former, the patient is admitted, and if in the course of a twelvemonth he or she recovers, all is well. but this is not always the case; far from it; and if still insane, they are discharged as incurable, and this very fact is sufficient to prevent their admission into the other. To the county asylums admission can be gained by the parochial authorities, and if no interest is to be had in the board-room, they will take care that the poor lunatic is literally a pauper before they will listen to any appeal for their intervention.

The working of the present system is seen in my own case. My wife is incurably insane. She has been discharged from St. Luke's, and I know of no public asylum where to place her; the consequence is, for the last three years I have had to maintain her in a private asylum, and as I am but a pensioner, with a little family, blind, and unable to add to my stipend, with no prospect of the expense terminating, I sometimes dare not trust myself to think of the future.

I trust, Sir, it will appear, that either a new institution is wanted for confirmed lunatics, or that the regulations of existing ones should be materially altered, especially with regard to an extension of time.

March, 1848.

The Hugbaxd of a Poor Lunatic.

\section{THE ENQUIRY AT THE QUEEN CHARLOTTE'S LYING-IN HOSPITAL. \\ To the Editor of Tha Larcer.}

SIR,-Your remarks on the correspondence of "Inquisitor" calls for an explanation from some of the parties interested; and as one of that number, I am ready to give, as far as I am able, that further information which you solicit, and which, very likely, I am better able to furnish than the inquisitorial gentleman, who, judging from the editorial remarks his letter has drawn forth, cannot be in possession of the full particulars of this "fracas."

The following statement I trust you will consider satisfactory, at least with respect to the necessity for a coroner's inquest, and that your readers may be satisfied likewise, I trust you will give this letter publication.

That I may not intrude upon your valuable time with any irrelevant matter, I will simply state, that last MIonday week a special committee of Queen Charlotte's Lying-in Hospital was summoned at the request of a gentleman who had interested himself in the complaints of a patient discharged from that hospital; but, upon its meeting, the majority of the committee present decided that he (not being a governor) had no right to address their Board; however, after some discussion, the honour of an audience was granted, and to the following effect he then addresssed the Board:-That he came forward to seek the fullest investigation of a serious charge laid by their hospital surgeon against a lady, who was the only visitor of a patient lately in that hospital, and he appealed to Dr. Ashburner to prove his assertion, that Mr. Gream had stated this patient to be "a vulgar, low beast," "that some low person came to the hospital, and brought something with her, when she administered it to the infant, which was succeeded by convulsions, and the child died soon afterwards." Mr. Gream immediately denied having said anything of the kind, but mentioned something about syrup of poppies being given to children; when, after a not very satisfactory, though long discussion, in which the charge was argued and contradicted, the Board were content with Mr. Gream's denial, (Dr. Ash burner still maintaining that the above-mentioned language had been used,) and expressed themselves perfectly satisfied that the child had died a natural death, and that there was not the slightest imputatation against the lady's character, who was afterwards complimented by one of the committee for the kind and charitable part she had acted in visiting this unfortunate woman, and supplying her with every necessary, under such distressing circumstances.

I will further state, that the certificate of death was given by Mr. Joseph Cholmondely, of 3, Nottingham-place, a gentleman, whose high standing in society, and whose superior medical acquirements, I am sure, will satisfy the most sceptical that no unfair play had been used to cause the death of this child.

Should you require further information, I shall be happy to furnish it as far as my certain knowledge will enable me; but I think the above statement (to which may be added that a post-mortem was made by a medical man, at the request of a party interested in the case) will be sufficient to convince the coroner of the non-necessity of holding an inquest on a body which is already under ground.-I remain, Sir, your obedient servant and constant reader, VEKITAs.

London, February, 1848.

** We should have published this letter earlier, but we thought it would be necessary, in the first instance, to make some inquiries on the subject. The resnlt inclines us to believe that the language of Mr. Gream had been unintentionally misrepresented; that the conduct of the parent of the child had not been reprehensible with respect to her offspring, and that the lady had only acted the part of a good Samaritan; in a word, we are inclined to believe that no wrong was done, and that there was no intention of wrong-doing.- $\mathrm{ED}$. L.

\section{COMPLAINT FROM CHARING-CROSS HOSPITAL. To the Editor of Tü Lancet.}

Sir,-Knowing your great impartiality, I have been induced to direct your attention to the following disadvantages under which the students of this hospital labour.

There have been neither dressers nor clinical clerks appointed of late years, for the alleged reason, that the gentlemen who formerly held these oftices were so inattentive to their duties; but perhaps the tme explanation is, their dnties were so few, that the offices were discontinued. Thelatter reason, however, cannot now hold good, since the number of patients has greatly increased; and it is unfair that we of the present day, willing to undertake the offices, and to acquire the practical advantages to be derived from them, should be prevented on the plea of the inattention of other persons in previous years.

Trusting you will find space in your valuable journal for the insertion of this note, I remain, Sir, yours, \&cc., March, 1848.

STUDENS.

\section{THE "HEAD AND HOME" SCHEME. To the Editor of Tre Lavcer.}

Sir,--Pray what does the rubbish agreed to by the quast heads of the profession mean? I cannot understand it. Do they intend to register members of the College only, or licentiates of the Hall only, or they only who have both qualifications? Do they mean to trounce a man who holds a degree of M.D. from Scotland, or from a foreign university, along with the College diplomas or Hall licence, or both if he presumes to add M.D. to his name ?-See clause twenty-one. 